\title{
Investigating Relative Permeability Measurements using Unsteady-State Core Flooding Method
}

\author{
Walid Mohamed Mahmud ${ }^{1}$, Saber Elmabrouk ${ }^{1}$, Hisham Khaled Ben Mahmud ${ }^{2}$ \\ ${ }^{1}$ Department of Petroleum Engineering, University of Tripoli, Libya \\ ${ }^{2}$ Department of Petroleum Engineering, Curtin University Malaysia
}

*Corresponding Author: Hisham Khaled Ben Mahmud, Department of Petroleum Engineering, Curtin University Malaysia

\begin{abstract}
The advances in coring and core analysis techniques provide the premise to measure required petrophysical properties and to acquire simultaneously other reservoir rock dependent parameters. The objective of coring and core analysis is to reduce uncertainty in reservoir evaluation by providing data representative of the reservoir conditions. Relative permeability data are essential to understanding multiphase flow in porous media and reservoir simulation that are usually obtained by steady-state flow or unsteady-state flow methods. In this study experiments were performed using unsteady-state method that considers the effect of fluid viscosity and average saturation at breakthrough. Three core plugs of different petrophysical properties were used to conduct core flooding tests where the variations in oil residual saturation and oil-water relative permeability were measured and compared with Johnson, Bossler and Naumanncorrelation, Pirson's correlation and Corey's model. Relative permeabilities and residual oil saturations obtained by Pirson's correlation were lower than those of Johnson, Bossler and Naumann correlation and Corey's model. It was observed that as core plug permeability increases, water breakthrough slightly increases.
\end{abstract}

Keywords: multiphase flow, relative permeability, residual oil saturation

\section{INTRODUCTION}

Oil recovery options are generally divided into three main stages: primary, secondary and tertiary recovery. In the initial oil production stage, primary oil recovery is a result of displacement energy that naturally occurs in reservoirs. These natural driving mechanisms include depletion, gas cap, water and combination drives. Secondary oil recovery takes place as oil production rate significantly decreases. The main purpose of secondary oil recovery is to control pressure in the reservoir to maintain or increase oil production rate by introducing external fluid to the reservoir. It is usually done with processes like water flooding or gas injection. Recovery factor from primary and secondary oil recovery is usually around $20-40 \%$ and is affected by reservoir rock properties, fluid properties and geological heterogeneities (Romero-Zerón, 2012). Tertiary oil recovery is considered if cost to production ratio of secondary oil recovery process becomes no longer economical. The ultimate target of tertiary oil recovery, also known as enhanced oil recovery (EOR) is to improve the overall oil sweep efficiency. In EOR processes, the recovery factor increases to about $30-60 \%$ (Sino Australia Oil and Gas Ltd, 2013). An EOR process increases hydrocarbon production by altering formation properties for conducive extraction (Needham and Doe, 1987). The true meaning of EOR is the ultimate oil recovery that can be recovered from a reservoir in a cost-effective manner on top of oil economically recovered after primary and secondary oil recoveries. Research and pilot testing are conducted to further develop different methods of EOR. These methods includethermal recovery and non-thermal methods such as chemical flooding, miscible flooding, immiscible gas drive and microbial treatment.

As wetting and non-wetting phases flow together in porous medium, each phase follows separate and distinct paths. The distribution of the two phases is according to their wetting characteristics. Because wetting phase occupies smaller pore openings at small saturations, and these pore openings only slightly contribute to flow, the presence of small wetting phase saturation would only affect nonwetting phase permeability to limited extent. And because non-wetting phase occupies central or 
larger pore openings that largely contribute to fluid flow through the reservoir, small non-wetting phase saturation would significantly reduce wetting phase permeability (Ahmed, 2010, Mahmud and Nguyen, 2006 and Mahmud et. al., 2007).

Relative permeability is an essential petrophysical property required for description of multiphase flow in petroleum reservoirs. It is a direct measure of the ability of porous medium to produce one fluid when two or more fluids are present. This flow property is a result of composite effects of porosity, pore geometry, wettability, saturation history, reservoir temperature, reservoir pressure, overburden pressure and rock type. Relative permeability curves are also important in the study of reservoir productivity (Pak and Sheikh, 2013). They are used in reservoir simulation modeling (Elmabrouk and Mahmud, 2016) and to predict production rate and recovery from reservoirs during all recovery stages (primary, secondary, and tertiary). There are two approaches for determining relative permeability curves from laboratory core flow tests: steady and unsteady state methods. In the unsteady-state method, a fluid is injected to displace another fluid present in the core. Steady-state test data processing is relatively simple, but experiments are tedious and lengthy because attaining steady state fluid saturations in the core requires long period of time following the initiation of tests under certain fluid injection rates. In contrast, unsteady-state laboratory tests can berapidly performed and the tests better represent real physics of the phenomenon. However, recording a number of parameters is neither possible during experiment nor data interpretation is straightforward.

Due to reservoir oil phase-behavior properties, chemical processes often require the injection of chemical formulation in order to displace and mobilize oil effectively by decreasing the interfacial tension between oil and other reservoir fluids. One of the most promising chemical processes is polymer flooding. Instead of using water to displace oil, polymer is used as an alternative to injection water. Polymer introduced to injection water affects the viscosity of displaced fluid and hence decreases mobility ratio, improves stratification efficiencies and frontal saturations. The relative flow rates of water and oil are altered by polymer solution, sweeping larger area of the reservoir and; therefore, more oil is in contact with the polymer solution and displaced to production wells. Implementing polymer flooding earlier at water breakthrough during water flood is more effective and efficient in recovering reservoir oil. Polymers are often used in addition to different enhance oil recovery processes, however, relative permeability characteristics must be known before any polymer treatment can be utilized.

The objectives of this work are to improve reliability of laboratory measurements of multiphase relative permeability at unsteady-state conditions and to investigate the influence of rock, fluid, and rock-fluid properties on multiphase relative permeabilities. Conventional and special core analyses were performed on three core plugs and an automated system for measuring volumes of oil and brine produced during unsteady-state core flooding is described. Relative permeability versus saturation functions was calculated from unsteady-state data using Johnson, Bossler and Naumann correlations, Pirson's correlations and Sandra simulation software.

\section{EXPERIMENTAL WORK}

Oil is injected into core plug that is $100 \%$ saturated with formation brine. Using iterative, trial- anderror techniques, injection rate is maintained sufficiently high to minimize the impact of capillary end effects on flow behavior. Fingering and channeling could occur during any experiment, but the complications of these effects have largely been ignored in two-phase relative permeability literature. Cumulative volume of injected fluid, cumulative volume of produced fluids and pressure drop across the core are measured throughout the experiment. To obtain relative permeability relationships, differentiation of volume and pressure data is required. Core plugs were initially conditioned to $\mathrm{S}_{w i}$ (usually beginning with a core plug $100 \%$ saturated with water) through the injection of oil until no additional water is expelled from the core plug. Only mobile oil, at this point, is present in the core plug. Once $\mathrm{S}_{w i}$ condition is reached, water injection proceeds at constant rate until no oil is produced.

Prepared core plugs were individually placed in a hydrostatic core holder and an overburden pressure was applied. Simulated formation brine was injected at top end face of the plug at constant flow rate using high performance liquid chromatography pump shown in Figure 1. Produced volumes, differential pressure, time and confining pressure were monitored and recorded. Brine flood was only terminated as water cut reached $99.98 \%$. As oil production ceased, permeability to water was measured and test was terminated 


\subsection{Core Flooding Set-Up}

The flooding set is identical to that utilized by Mahmud (Mahmud, 2017) as shown in Figure 1. It consisted of the following equipments.

\subsubsection{Core Holder}

Core holder assembly comprised of stainless steel $48 \mathrm{~cm}$ long. Core holder is installed on a metal frame stand that allowed core holder to be placed in a horizontal or vertical position as required by user as shown in Figure 2. Length of core holder was enough to allow the use of longer cores of size $21 \mathrm{~cm}$. Both end caps of core holder have one port for either injection and production of fluids, and face of end caps are equipped with flow distributors to allow an even injection or production at the entire area of the core. Annular space between sleeve and core holder was filled with high viscosity paraffin that was used to provide a constant overburden pressure on the core.

\subsubsection{Overburden Pressure Equipment}

Pressure around rubber sleeve was maintained using viscous paraffin that has a viscosity of around $120 \mathrm{cp}$ at room temperature. The paraffin was stored in a cylinder equipped with floating piston. The pressure was provided by distilled water behind the piston using Quizix positive displacement pump. Thus, it is possible to keep a constant overburden pressure by recovering any extra paraffin due to expansion at higher temperatures during experiments. Pressure gauge placed on paraffin line to the core holder to show pressure readings.

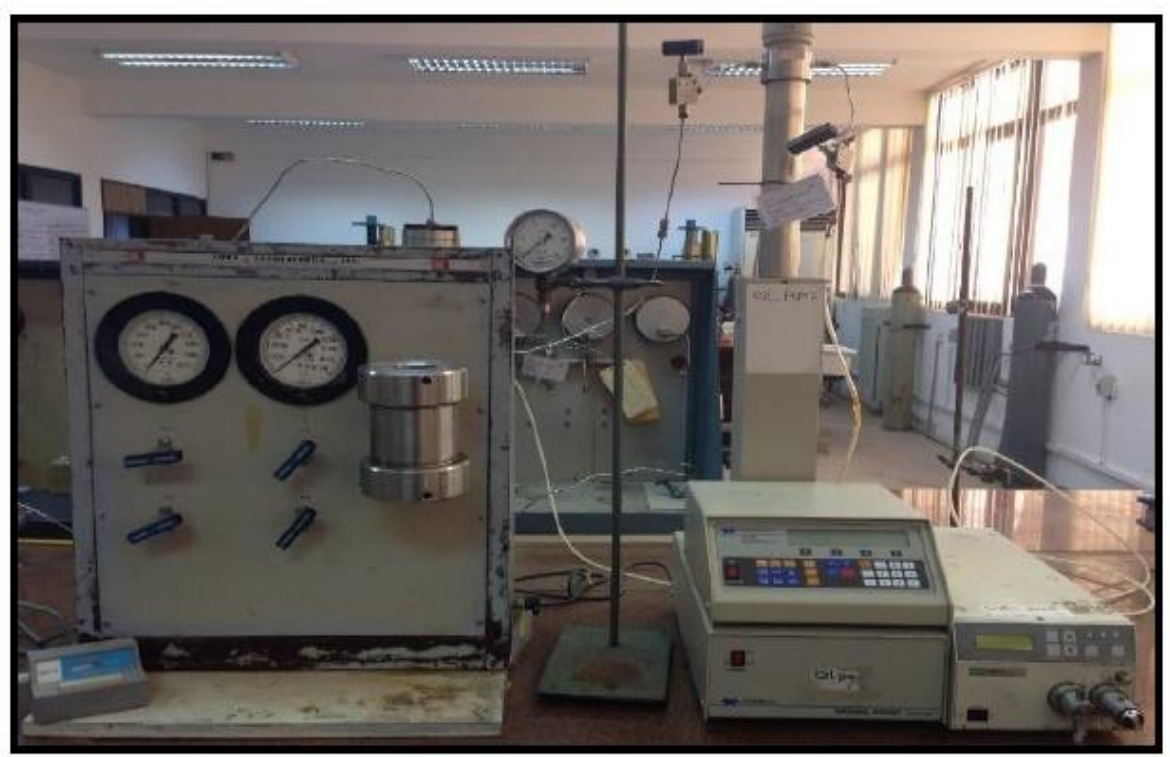

Figure 1. High performance liquid chromatography pump

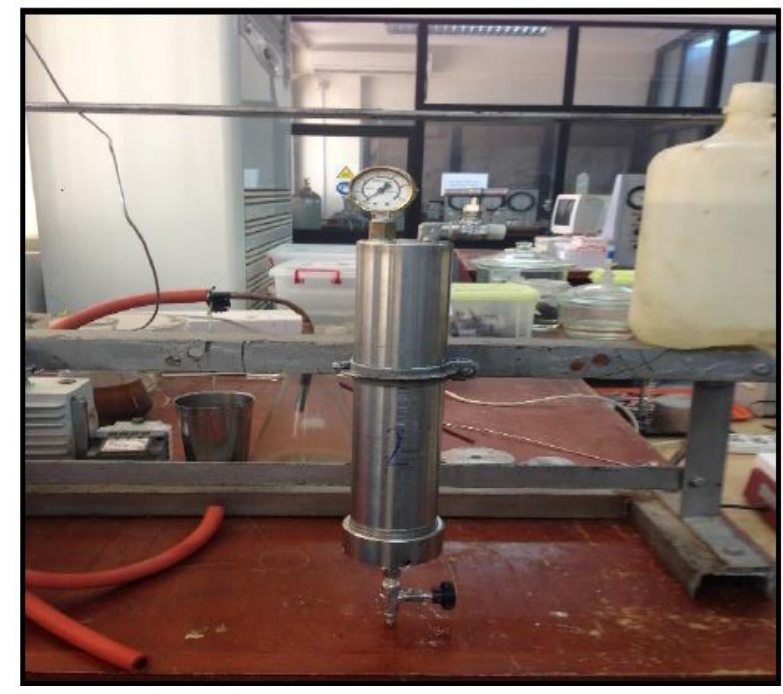

Figure 2. Core holder 


\subsubsection{Flooding Sequence and Procedures}

The packed porous media was installed inside the core holder. After providing the overburden pressure for starters, next step oil was injected at constant rate to initialize the core and calculate initial water saturation. Oil injection continued at $\mathrm{S}_{\mathrm{wi}}$ to measure effective oil permeability. The front was always sharp and no more water production was observed after the oil breakthrough. After initializing the core, a separator was connected and an imbibition displacement was initiated by injecting water at constant rate. During water injection phase, oil production was recorded versus time visually through the graduated glass tube of the separator, and pressure differential across the core was continuously monitored. Mass of water accumulated on the digital scale represented the total oil and water production. Water injection continued until desired pore volumes of the packed core. At experiment termination, the separator was disconnected and held at $40^{\circ} \mathrm{C}$ temperature for a few days in order for the oil/water meniscus to be completely separated and any possible adjustment to the final oil recovery to be performed.

After the routine core analysis and core flooding procedure were completed, the following results, tabulated in Table 1, were obtained.

Table 1. Core data summery

\begin{tabular}{|c|l|l|c|c|c|c|}
\hline Core plug & Lithology & Wettability & $\mathrm{Kg}, \mathrm{mD}$ & $\mathrm{K}_{\infty}, \mathrm{mD}$ & $\phi, \%$ & Swi \\
\hline 1 & Carbonate & Water-wet & 8.89 & 6.89 & 19.5 & 0.435 \\
\hline 2 & Carbonate & Water-wet & 237 & 223.739 & 21.5 & 0.194 \\
\hline 3 & Carbonate & Intermediate wettability & 14.73 & 11.7707 & 19.676 & 0.291 \\
\hline
\end{tabular}

\subsection{Relative Permeability Calculations}

After flooding sequence and procedures were completed, all required data were gathered for relative permeability calculations using the following methods.

\subsubsection{Johnson, Bossler And Naumann(JBN) Correlation}

It can be summarized in three steps. The pore volume injection obtained by Equation (1)

$$
\mathrm{Pv}_{\mathrm{inj}}=(\mathrm{Wi}) /(\mathrm{Pv})
$$

Where:

Pvinj $=$ Pore volume injection

$\mathrm{Wi}=$ Cumulative water injected, $\mathrm{cc}$

Average water saturation at the outlet face of the rock samples obtained by Equation (2)

of the Welge method:

$$
\overline{\mathrm{S}_{\mathrm{w}}}=\mathrm{S}_{\mathrm{wi}}+(\mathrm{Np} / \mathrm{Pv})
$$

Where:

$\mathrm{Np}=$ Cumulative oil production

Swi= Initial water saturation, fraction

$\overline{S_{w}}=$ average water saturation at the outlet face of the rock samples, fraction

Welge showed that displacing phase saturation at downstream at the end of the core $\left(\mathrm{S}_{\mathrm{w}_{2}}\right)$ can be related to average displacing phase saturation $\left(\overline{S_{w}}\right)$, fractional flow of the displaced phase $\left(f_{o}\right)$ and pore volume injected as:

$$
\mathrm{S}_{\mathrm{w}_{2}}=\overline{\mathrm{S}_{\mathrm{w}}}-\left(f_{o} * \mathrm{Wi}\right)
$$

Where:

$\mathrm{S}_{\mathrm{w}_{2}}=$ Saturation at downstream at the end of core, fraction

$f_{\mathrm{o}}=$ fractional flow of the displaced phase, fraction 
Because fractional flow of oil is equal to the slope of the tangent line at any given injection, it is calculated from the average and intercept saturations:

$$
f_{o}=\left(\Delta \mathrm{S}_{\mathrm{w}}\right) /\left(\Delta \mathrm{PV}_{\mathrm{inj}}\right)
$$

Also,

$$
f_{w}=1-f_{o}
$$

Where:

$f w=$ fractional flow of the displacing phase, fraction

Average oil viscosity obtained by Darcy's Law for each pressure drop:

$$
\mu_{0}=\left(\mathrm{Ko}^{*} \mathrm{~A} * \Delta \mathrm{P}_{\mathrm{inj}}\right) /(\mathrm{q} * \mathrm{~L} * 14700)
$$

Where:

$\mu_{0}=$ Average oil viscosity obtained, $\mathrm{cp}$

Ko $=$ Oil permeability, $\mathrm{mD}$

$\mathrm{Q}=$ Flow rate, $\mathrm{cc} / \mathrm{sec}$

Effective viscosity as function of average oil viscosity and pore volume injected:

$$
\lambda=\left(\overline{\mu_{0}}\right)-\left(\left(\Delta \overline{\mu_{0}} / \Delta \mathrm{Pv}_{\text {inj }}\right) * \mathrm{Pv}_{\text {inj }}\right)
$$

Where:

$\lambda=$ Effective viscosity, $\mathrm{cp}$

Finally, calculation of relative permeabilities from the following equations:

$$
\begin{aligned}
& \mathrm{K}_{\mathrm{ro}}=\left(\mu_{\mathrm{o}} * f_{o}\right) / \lambda \\
& \mathrm{K}_{\mathrm{rw}}=\left(\mu_{0} * f_{w}\right) / \lambda
\end{aligned}
$$

\subsubsection{Pirson's Correlation}

Pirson (1958) derived, from petrophysical considerations, generalized relationships for determining wetting and non-wetting phase relative permeabilities for both imbibition and drainage displacements. The generalized expressions are applied for water-wet rocks (Ahmed, 2010).

For water-wet phase:

$$
\mathrm{K}_{\mathrm{rw}}=\left(\sqrt{\mathrm{S}_{\mathrm{w}}} *\right)\left(\mathrm{S}_{\mathrm{w}}\right)^{3}
$$

The above expression is valid for both the imbibition and drainage displacement.

For non-wettig phase:

For Imbibition

$$
\mathrm{K}_{\mathrm{ro}}=\left(1-\left(\left(\mathrm{S}_{\mathrm{w}}-\mathrm{S}_{\mathrm{wc}}\right) /\left(1-\mathrm{S}_{\mathrm{wc}}-\mathrm{S}_{\mathrm{or}}\right)\right)\right)^{2}
$$

Where

$$
\mathrm{S}_{\mathrm{w}} *=\left(\mathrm{S}_{\mathrm{w}}-\mathrm{S}_{\mathrm{wc}}\right) /\left(1-\mathrm{S}_{\mathrm{wc}}\right)
$$

\subsubsection{Corey's Model}

Corey (1954) proposed simple mathematical expressions for generating relative permeability data of water-oil system. The approximation is good for imbibition displacement, water-displacing oil (Ahmed, 2010).

$$
\begin{aligned}
& \mathrm{K}_{\mathrm{rw}}=\mathrm{K}_{\mathrm{rw}, \text { sor }}\left[\left(\mathrm{S}_{\mathrm{w}}-\mathrm{S}_{\mathrm{wi}}\right) /\left(1-\mathrm{S}_{\mathrm{wi}}-\mathrm{S}_{\mathrm{or}}\right)\right]^{\wedge} \mathrm{C}_{\mathrm{w}} \\
& \mathrm{K}_{\mathrm{ro}}=\mathrm{K}_{\mathrm{ro}, \text { swi }}\left[\left(1-\mathrm{S}_{\mathrm{w}}-\mathrm{S}_{\mathrm{or}}\right) /\left(1-\mathrm{S}_{\mathrm{wi}}-\mathrm{S}_{\mathrm{or}}\right)\right]^{\wedge} \mathrm{C}_{\mathrm{o}}
\end{aligned}
$$


Where:

$\mathrm{C}_{\mathrm{w}}$ and $\mathrm{C}_{\mathrm{o}}=$ Corey exponents

\section{METHODOLOGY AND ANALYSIS}

As detailed in section 2.1.3, Table 2 shows routine and special core analyses data.

Table 2. Routine and special core analyses

\begin{tabular}{|c|c|c|c|}
\hline Parameters & Core plug 1 & Core plug 2 & Core plug 3 \\
\hline $\mathrm{L}, \mathrm{cm}$ & 4.9 & 5.21 & 4.89 \\
\hline $\mathrm{D}, \mathrm{cm}$ & 11.4 & 3.87 & 3.87 \\
\hline $\mathrm{A}, \mathrm{cm}^{2}$ & 57.1142 & 11.7 & 11.7676 \\
\hline $\mathrm{Bv}, \mathrm{cc}$ & 45.9287 & 60.6933 & 57.2513 \\
\hline $\mathrm{Gv}, \mathrm{cc}$ & 2.67495 & 47.3321 & 45.9866 \\
\hline $\mathrm{Pg}, \mathrm{gm} / \mathrm{cc}$ & 11.19 & 2.6672 & 2.6628 \\
\hline $\mathrm{Pv}, \mathrm{cc}$ & 19.5 & 13.3612 & 11.2647 \\
\hline$\phi, \%$ & 3.81 & 21.5 & 19.6759 \\
\hline $\mathrm{Swi}, \%$ & 43.5 & 19.4 & 29.1 \\
\hline $\mathrm{Kg}, \mathrm{mD}$ & 8.89 & 237 & 14.73 \\
\hline $\mathrm{K} \infty, \mathrm{mD}$ & 6.89 & 223.74 & 11.77 \\
\hline $\mathrm{Ko}, \mathrm{mD}$ & 4.3901 & 99.6057 & 6.774 \\
\hline $\mathrm{Kw}, \mathrm{mD}$ & 2.848 & 37.7825 & 3.9425 \\
\hline Lithology & Carbonate & Carbonate & Carbonate \\
\hline Wettability & Water-wet & Water-wet & Intermediate \\
\hline
\end{tabular}

\section{RESUlTS AND DISCUSSION}

Relative permeability measurements for the three core plugs were conducted at constant flow rate and conditions of saturation and pressure. Water and oil were utilized as multiphase fluids. In each experiment, flow was continued at constant rate until the displacement was completed, at which time series of readings were taken and relative permeability values to each case were calculated.

\section{Core plug \#1}

Measurements were conducted on a $6.9 \mathrm{mD}$ core. In unsteady-state displacement, water was pumped through the core to $100 \%$ brine saturation then oil was pumped through the coreto obtain oil permeability at initial water saturation. After the last step brine was again pumped through the core at constant flow rate resulting in $0.013 \%$ and $99 \%$ fractional flow of oil and water respectively and breakthrough saturation of $78 \%$ as illustrated in Figure 3.Unsteady state data achieved from the core flood experiment are presented in Table 3. Average saturations were measured by Welge correlation with an initial saturation of $43.5 \%$. After conditions in the core was equilibrated at $0.013 \%$ oil fractional flow, data gathered were used to measure the relative permeability curves by JBN and Pirson correlations and Corey's model.

Relative permeability crossover obtained from JBN correlations was above 50\% water saturation which indicates water wet system, Corey and Pirson correlations results gave a cross-over points over $50 \%$ water saturation which also indicates water-wet system. Moreover, JBN and Pirson correlations indicate 15\% residual oil saturation which indicates good oil production at the end of water flooding process. Corey's model, however, yields 5\% lower residual oil saturation as shown in Figure 4.

Table 3. Data obtained from the core flood procedure

\begin{tabular}{|c|c|c|c|c|c|}
\hline Water vol. & Oil increment & Total increment & Inj.Press & CumOil & CumTot \\
\hline $\mathrm{cc}$ & $\mathrm{cc}$ & $\mathrm{cc}$ & Psi & $\mathrm{cc}$ & $\mathrm{cc}$ \\
\hline 0 & 2.65 & 2.65 & 158 & 2.65 & 2.65 \\
\hline 0.05 & 1.35 & 1.4 & 150 & 4 & 4.05 \\
\hline 2.1 & 0.45 & 2.55 & 142 & 4.45 & 6.6 \\
\hline 5.2 & 0.1 & 5.3 & 130 & 4.55 & 11.9 \\
\hline 7.3 & 0.07 & 7.37 & 123 & 4.62 & 19.27 \\
\hline 11.8 & 0.05 & 11.85 & 110 & 4.67 & 31.12 \\
\hline 18.55 & 0.05 & 18.6 & 98 & 4.72 & 49.72 \\
\hline 22.9 & 0.04 & 22.94 & 88 & 4.76 & 72.66 \\
\hline 49.54 & 0.04 & 49.58 & 75 & 4.8 & 122.24 \\
\hline 72.79 & 0.01 & 72.8 & 70 & 4.81 & 195.04 \\
\hline
\end{tabular}


Relative permeability cross-over obtained from JBN correlations was above $50 \%$ water saturation which indicates water wet system, Corey and Pirson correlations results gave a cross-over points over $50 \%$ water saturation which also indicates a water-wet system. Moreover, JBN and Pirson correlations indicates $15 \%$ residual oil saturation which indicates good oil production at the end of water flooding process. Contrasting, Corey correlation, however, yields 5\% lower residual oil saturation as shown in Figure 4.

\section{Core plug \#2}

Measurements were conducted on $223.73 \mathrm{mD}$ core. Water was pumped through the core to a $100 \%$ brine saturation then the oil was pumped through the core to obtain oil permeability at initial water saturation. Brine was again pumped through the core at a constant flow rate, ending up with $0.006 \%$ and $99 \%$ fractional flow of oil and water respectively, the breakthrough saturation was 0.63 as shown in Figure 5. The unsteady state data achieved from the core flood experiment are presented in Table 4.

Average saturations were measured by Welge correlation at an initial saturation of $19.4 \%$. After conditions in the core had equilibrated at $0.006 \%$ oil fractional flow, data gathered were used to measure relative permeability curves by JBN, Pirson, and Corey's correlations as shown in Figure 6. Relative permeability crossover point obtained from JBN correlations was slightly higher than 50\% water saturation which indicates water-wet system.

Average saturations were measured by Welge correlation at an initial saturation of $19.4 \%$. After conditions in the core had equilibrated at $0.006 \%$ oil fractional flow. Data gathered were used to measure the relative permeability curves by JBN, Pirson, and Corey correlations as shown in Figure 6. Relative permeability crossover point obtained from JBN correlations was a little higher than 50\% water saturation which indicates a water-wet system. Likewise, Corey and Pirson correlations results gave close results with crossover points over $50 \%$ water saturation which also indicates a water-wet system. Residual oil saturation in JBN and Pirson correlations indicate 35\% at the end of water flooding displacement whereas Corey correlations gave an almost 5\% lower residual oil saturation as shown in Figure 6.

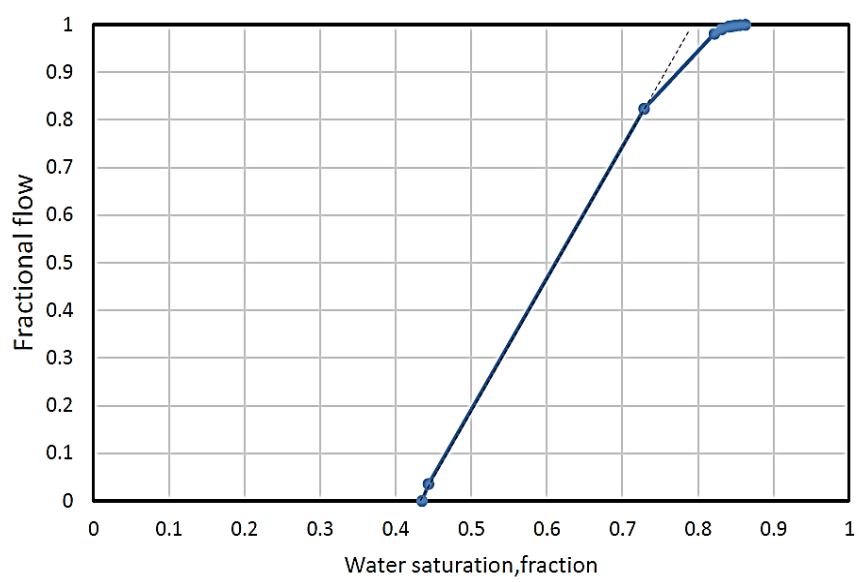

Figure 3. Fractional flow versus wetting phase for core plug 1

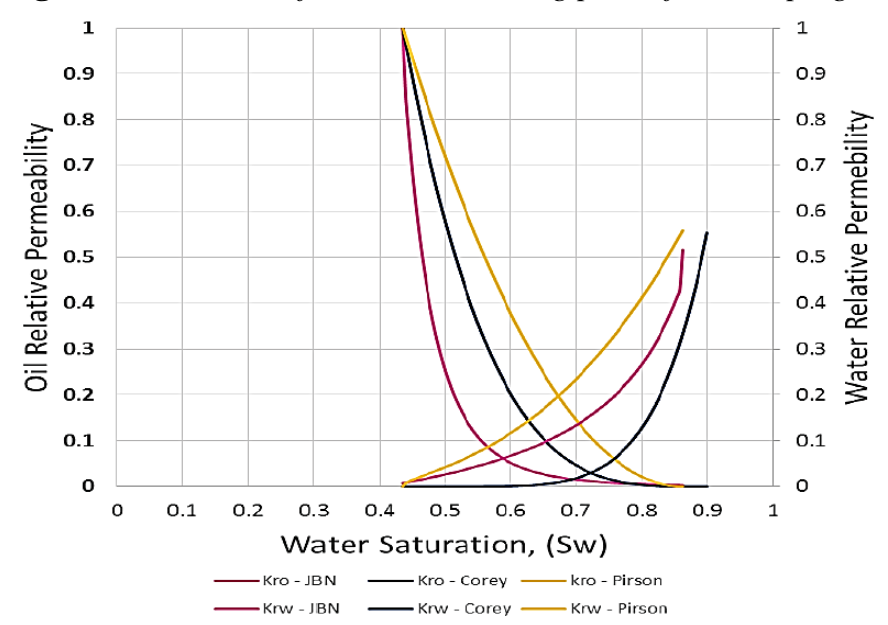

Figure 4. Relative permeability curves for core plug 1 
Table 4. Data obtained from core flood procedures

\begin{tabular}{|c|c|c|c|c|c|c|}
\hline Cum .Time & Water vol & Oil increment & Total increment & Inj.Press & Cum.Oil & Cum Tot \\
\hline sec & cc & cc & cc & Psi & cc & cc \\
\hline 361.0000 & 0.0000 & 2.5000 & 2.5000 & 6.5000 & 2.5000 & 2.5000 \\
\hline 617.0000 & 0.0000 & 2.6000 & 2.6000 & 15.7000 & 5.1000 & 5.1000 \\
\hline 667.0000 & 0.1000 & 0.5500 & 0.6500 & 20.3000 & 5.6500 & 5.7500 \\
\hline 1002.0000 & 5.4700 & 0.0300 & 5.5000 & 17.8000 & 5.6800 & 11.2500 \\
\hline 1317.0000 & 5.2900 & 0.0200 & 5.3100 & 16.5000 & 5.7000 & 16.5600 \\
\hline 1847.0000 & 8.6600 & 0.0300 & 8.6900 & 15.2000 & 5.7300 & 25.2500 \\
\hline 2359.0000 & 8.5800 & 0.0200 & 8.6000 & 13.5000 & 5.7500 & 33.8500 \\
\hline 2920.0000 & 9.3800 & 0.0200 & 9.4000 & 12.1000 & 5.7700 & 43.2500 \\
\hline 3682.0000 & 12.6600 & 0.0200 & 12.6800 & 10.0000 & 5.7900 & 55.9300 \\
\hline 4725.0000 & 17.4000 & 0.0200 & 17.4200 & 9.1000 & 5.8100 & 73.3500 \\
\hline 6145.0000 & 23.5000 & 0.0200 & 23.5200 & 8.2000 & 5.8300 & 96.8700 \\
\hline 9045.0000 & 48.0600 & 0.0300 & 48.0900 & 7.4000 & 5.8600 & 144.9600 \\
\hline 13540.0000 & 74.1400 & 0.0300 & 74.1700 & 6.6000 & 5.8900 & 219.1300 \\
\hline 19785.0000 & 98.0900 & 0.0200 & 98.1100 & 5.9000 & 5.9100 & 317.2400 \\
\hline 28690.0000 & 148.1000 & 0.0100 & 148.1100 & 5.7000 & 5.9200 & 465.3500 \\
\hline
\end{tabular}



Figure 5. Fractional flow versus wetting phase for core plug 2

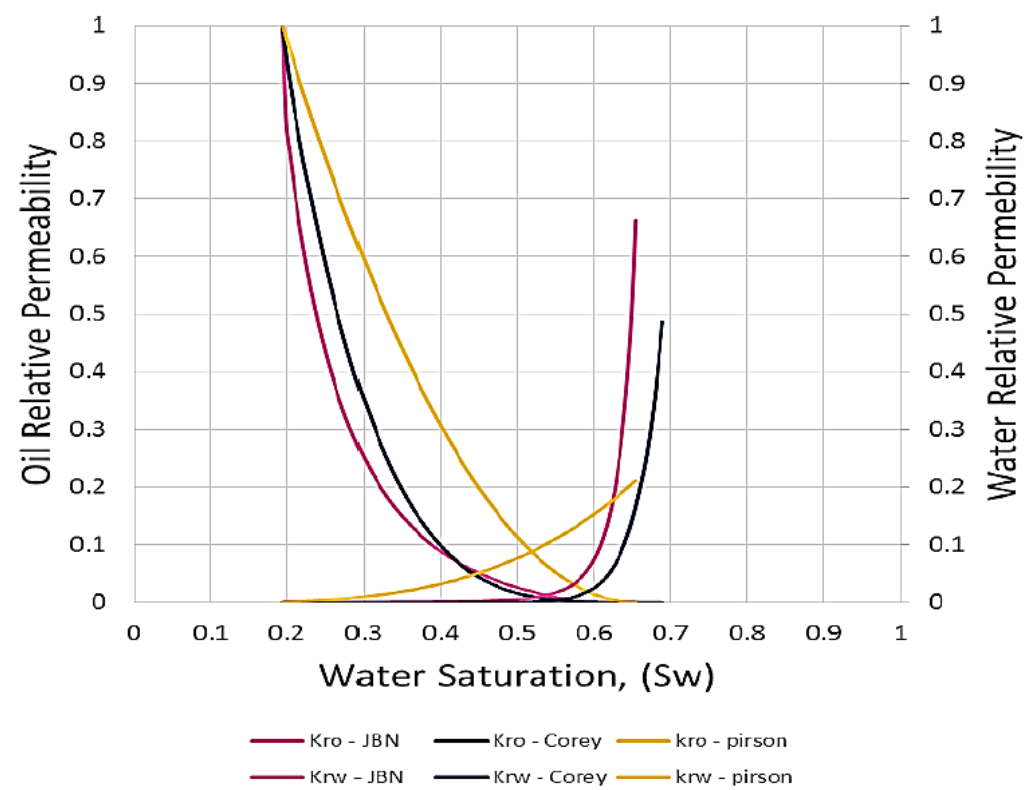

Figure 6. Relative permeability curves for core plug 2 


\section{Core plug \#3}

Measurements were conducted on $11.77 \mathrm{mD}$ core. Water was pumped through the core to $100 \%$ brine saturation then oil was pumped through the core to obtain oil permeability at initial water saturation. Brine was pumped again through the core at constant flow rate yielding $0.015 \%$ and $99 \%$ fractional flow of oil and water respectively and breakthrough saturation was 0.52 as shown in Figure 7 . Average saturations were measured by Welge correlation at an initial saturation of 0.291.After conditions in the core had equilibrated at $0.015 \%$ oil fractional flow. Data shown in Table 5 were used to measure relative permeability curves by JBN, Pirson and Corey's correlations.

Relative permeability cross-over points obtained from JBN and Corey's correlations was less than $50 \%$ water saturation which indicates an intermediate wet tability system, however; Pirson correlation gave only a slight increase in cross-over point above 50\% which also indicates an intermediate wet tability system as shown in Figure 8. JBN and Pirson correlations indicate around 45\% residual oil saturation at the end of water flooding displacement. Moreover, Corey's correlation provides around $5 \%$ lower residual oil saturation.

After obtaining relative permeability curves for all core plugs, an identical residual oil saturation end points values were obtained from JBN and Pirson correlations and slightly different values obtained from Corey's model. Pirson correlation yielded different relative permeability values compared to JBN correlation and Corey's model.

Table 5. Data obtained from core flood procedures

\begin{tabular}{|c|c|c|c|c|c|c|}
\hline Cum.Time & Water vol & Oil increment & Total increment & Inj.Press & CumOil & Cum Tot \\
\hline $\mathrm{sec}$ & $\mathrm{cc}$ & $\mathrm{cc}$ & $\mathrm{cc}$ & Psi & $\mathrm{cc}$ & $\mathrm{cc}$ \\
\hline 596 & 0 & 2.4 & 2.4 & 90 & 2.4 & 2.4 \\
\hline 948 & 1.425 & 0.1 & 1.525 & 88 & 2.5 & 3.925 \\
\hline 1150 & 2.35 & 0.05 & 2.4 & 85 & 2.55 & 6.325 \\
\hline 1550 & 5.09 & 0.08 & 5.17 & 81 & 2.63 & 11.495 \\
\hline 1970 & 5.5 & 0.05 & 5.55 & 77 & 2.68 & 17.045 \\
\hline 2570 & 8.37 & 0.05 & 8.42 & 73 & 2.73 & 25.465 \\
\hline 3460 & 12.89 & 0.04 & 12.93 & 69 & 2.77 & 38.395 \\
\hline 4615 & 17.15 & 0.05 & 17.2 & 62 & 2.82 & 55.595 \\
\hline 9215 & 67.1 & 0.07 & 67.17 & 55 & 2.89 & 122.765 \\
\hline 14190 & 75.55 & 0.05 & 75.6 & 51 & 2.94 & 198.365 \\
\hline 21030 & 98.14 & 0.04 & 98.18 & 48 & 2.98 & 296.545 \\
\hline 30500 & 147.89 & 0.04 & 147.93 & 45 & 3.02 & 444.475 \\
\hline 44600 & 198.2 & 0.03 & 198.23 & 43 & 3.05 & 642.705 \\
\hline
\end{tabular}

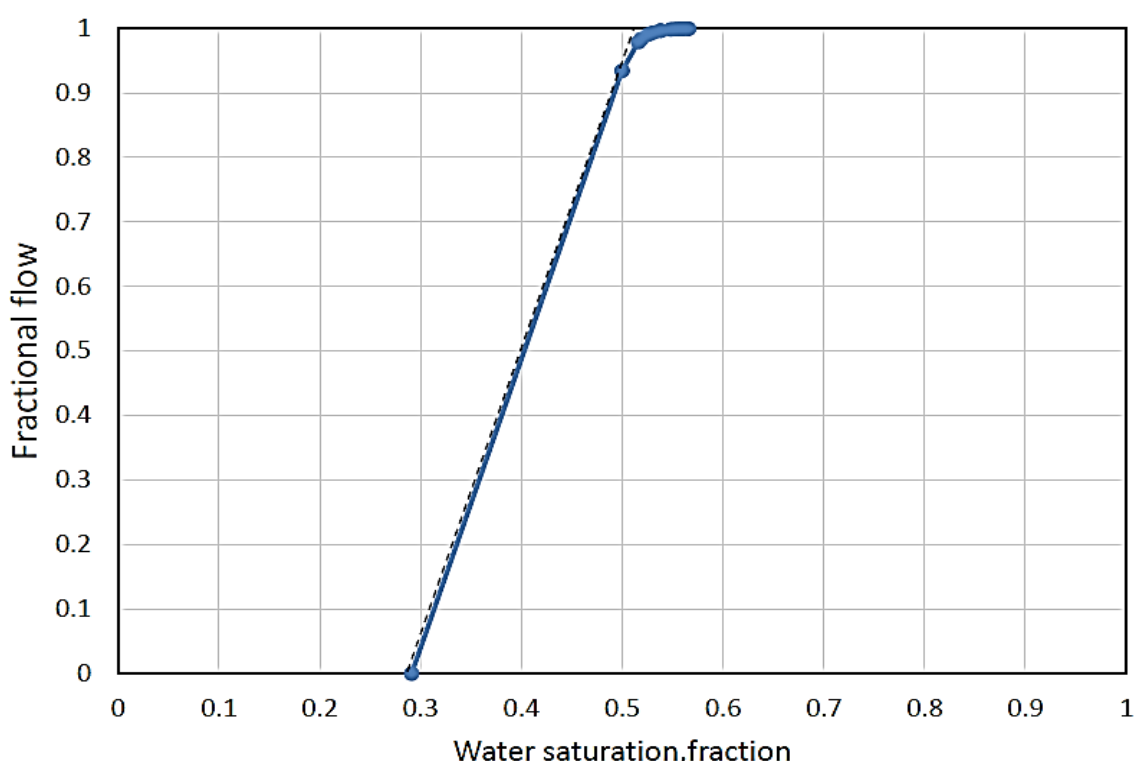

Figure 7. Fractional flow versus wetting phase for core plug 3 


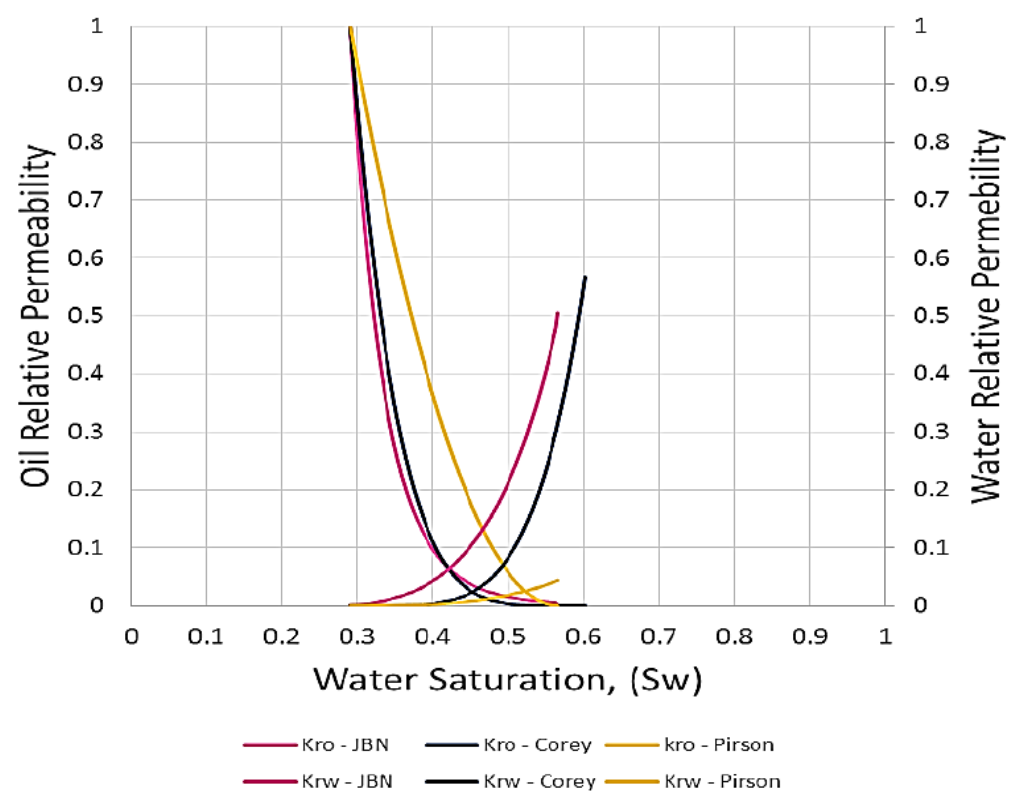

Figure 8. Relative permeability curves for core plug 3

\section{CONCLUSION}

Relative permeability is one of essential tools to predict the performance of reservoirs produced by water flood or natural water drive. It is necessary to average relative permeability data obtained from different rock samples before utilization. The main conclusions obtained from this study are:

1. The most accurate relative permeability measurements are made on a native-state core, where reservoir wet tability is preserved. If such core is unavailable, the core should be cleaned and restored because massive errors could occur if wet tability is altered.

2. Recent unsteady state displacement technique has enabled data obtained from such relatively simple and inexpensive experiments to have much wider application and improved accuracy when correlated with data obtained from more expensive and time consuming steady state experiments.

3. Relative permeability verses water saturation revealed that core plugs 1 and 2 were water-wet while core plug 3 was intermediately wet.

4. In the intermediately wet plug, water initially flows through largest flow channels, oil relative permeability $\left(\mathrm{K}_{\mathrm{ro}}\right)$ decreases and water relative permeability $\left(\mathrm{K}_{\mathrm{rw}}\right)$ rapidly increases.

5. The unsteady-state method was performed at low flooding rate. Water-wet core plugs were characterized by limited oil production after water breakthrough, however, generally good recoveries and low water relative permeability values at residual oil saturation.

6. Relative permeability data obtained from Pirson correlation gave somewhat different results than the other two methods.

\section{REFERENCES}

[1] Ahmed, T. H., Reservoir engineering handbook. $4^{\text {th }}$ ed, Amsterdam, Boston, 2010.

[2] Laura, R. Z., Introduction to Enhanced Oil Recovery (EOR) Processes and Bioremedation of OilContaminated Sites, 2012.

[3] Mahmud, W. M. and Nguyen,V. H.: "Effects of Snap-Off in Imbibition in Porous Media with Different Spatial Correlations," Transport in Porous Media, Volume 64, Number 3, September 2006, 279-300.

[4] Mahmud, W. M., Arns, J. Y., Sheppard A., Knackstedt,M. A. and Pinczewski,W. V.: "Effect of Network Topology on Two-Phase Imbibition Relative Permeability", Transport in Porous Media, Volume 66, Number 3, February 2007, 481-493.

[5] Mahmud, W. M., Effect of network topology on relative permeability, network model and experimental approaches. International Journal of Oil, Gas, and Coal Engineering, 2017, 5 (5); 90 - 96.

[6] Needham, R. B. and Doe, P. H. 1987. Polymer Flooding Review. J Pet Technol 39 (12): 1503-1507. SPE17140-PA. http://dx.doi.org/10.2118/17140-PA. 
[7] Pak A. and Sheikh B, Study of relative permeability variation during unsteady flow in saturated reservoir rock using Lattice Boltzmann method, Department of Civil Engineering, Sharif University of Technology, Tehran, Iran,2013.

[8] Elmabrouk, S. and Mahmud,W. M. "Reservoir Management Strategies for Development of Water Injection Planning Project", paper presented at the International Conference on Industrial Engineering and Operations Management, Detroit, September 23-25, 2016.

[9] The Petroleum Society of the Canadian institute of mining, metallurgy and petroleum, determination of oil and gas reserves, 1994.

\section{AUTHORS' BIOGRAPHY}



Dr. Walid Mohamed Mahmud, is currently an Assistant Professor at the Department of Petroleum Engineering, University of Tripoli, Libya. In addition to teaching several undergraduate and postgraduate petroleum engineering courses, Dr. Mahmud has supervised numerous undergraduate and postgraduate graduation projects. Dr. Mahmud is the Department Quality Control and Assurance Coordinator.

Dr. Mahmud's main research interests include, but not limited to, multiphase flow in porous media, network modeling and relative permeability laboratory measurements.

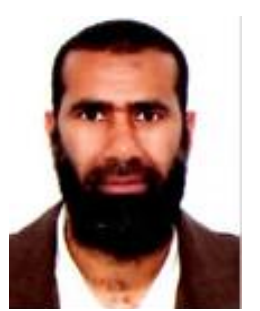

Hisham Khaled Ben Mahmud, has achieved Bachelor, Master and $\mathrm{PhD}$ degree in Chemical Engineering from Tripoli University, Sydney University and Curtin University, Australia, respectively. Also I have gained Graduate Diploma in oil and gas from University of Western Australia (UWA). I have expertise in modelling multiphase flow into subsea systems such as pipeline, jumper, riser evaluating pressure drop, and liquid holdup. Also optimize the risk of hydrate blockages into bend pipes. Recently I have involved into upstream research area including reservoir matrix acidizing, experimentally injecting a fluid (acid) into a core sample (sandstone or carbonate) to improve reservoir properties (porosity, permeability) observing wormhole and precipitation reaction. Another area I involve in is enhanced oil recovery (EOR) in brown oil field using different injecting fluids ( $\mathrm{CO} 2$, water, polymer, surfactant) or modify production wells in order to improve hydrocarbon fluid recovery by minimizing oil wettability, surface tension and increase contact area.

Citation: Hisham Khaled Ben Mahmud et al, (2017). Investigating Relative Permeability Measurements using Unsteady-State Core Flooding Method, International Journal of Petroleum and Petrochemical Engineering (IJPPE), 3(4), pp.54-64, DOI: http://dx.doi.org/10.20431/2454-7980.0304005

Copyright: () 2017 Hisham Khaled Ben Mahmud and Yuhashinee Ravichandran. This is an open-access article distributed under the terms of the Creative Commons Attribution License, which permits unrestricted use, distribution, and reproduction in any medium, provided the original author and source are credited 